\title{
Screening of freshwater and seawater microalgae strains in fully controlled photobioreactors for biodiesel production
}

\author{
A. Taleb ${ }^{a, b, c}$, R. Kandilian ${ }^{a}$, R. Touchard ${ }^{a}$, V. Montalescot ${ }^{a}$, T. Rinaldi $^{a}$, S. Taha ${ }^{b}$, H. Takache ${ }^{c}$, L. Marchal $^{a}$, \\ J. Legrand ${ }^{a}$, J. Pruvost ${ }^{a, *}$ \\ ${ }^{a}$ GEPEA, Université de Nantes, CNRS UMR6144, bd de l'Université, CRTT, BP 406, 44602 Saint-Nazaire Cedex, France \\ ${ }^{\mathrm{b}}$ AZM Center for Biotechnology Research and Its Applications, Laboratory of Applied Biotechnology, Lebanese University, EDST, Tripoli, Lebanon \\ ${ }^{\mathrm{c}}$ Department of Food Science and Technology, Faculty of Agricultural and Veterinary Medicine, Lebanese University, Dekweneh, Beirut, Lebanon
}

- A screening procedure was developed to select an optimal strain for biodiesel production.

- TAG productivity and cell fragility, affecting TAG recovery in wet environment, were considered.

- 14 seawater and freshwater microalgae strains were screened.

- Large variation between the strains on numerous screening criteria was found.

- N. gaditana and P. kessleri were found to be the most promising strains for biodiesel production.

\begin{abstract}
A B S T R A C T
Strain selection is one of the primary hurdles facing cost-effective microalgal biodiesel production. Indeed, the strain used affects both upstream and downstream biodiesel production processes. This study presents a screening procedure that considers the most significant criteria in microalgal biodiesel production including TAG production and wet extraction and recovery of TAGs. Fourteen freshwater and seawater strains were investigated. Large variation was observed between the strains in all the screening criteria. The overall screening procedure ultimately led to the identification of Parachlorella kessleri UTEX2229 and Nannochloropsis gaditana CCMP527 as the best freshwater and seawater strains, respectively. They featured the largest areal TAG productivity equal to $2.7 \times 10^{-3}$ and $2.3 \times 10^{-3} \mathrm{~kg} \mathrm{~m}^{-2} \mathrm{~d}^{-1}$. respectively. These two strains also displayed encouraging cell fragility in a high pressure bead milling process with $69 \%$ and $98 \%$ cell disruption at 1750 bar making them remarkable strains for TAG extraction in wet environment.
\end{abstract}

\section{Introduction}

Global warming, the fear of exhausting petroleum resources, and the potential of an increase in fossil fuels prices are major worldwide concerns for the future of energy security and independence. Within this context, research efforts have focused over the last thirty years on developing alternative, or renewable, fuels for use in the transportation sector (Chisti, 2007, 2008). Recently, microalgae have appeared as a sustainable vegetal source for biofuels production including biodiesel (Chisti, 2007; Hu et al., 2008). Compared to terrestrial plants, these photosynthetic

\footnotetext{
* Corresponding author.

E-mail address: jeremy.pruvost@univ-nantes.fr (J. Pruvost).
}

microorganisms enjoy much larger theoretical yields of biomass per hectare, more intracellular lipid content (Mata et al., 2010; Taleb et al., 2015), and a metabolic flexibility reflecting the enhancement of the intracellular accumulation of lipids by varying the culture conditions. For example, nutrient stress such as nitrogen deficiency can trigger the accumulation of large amounts of neutral lipids in the form of TAGs, which are the suitable feedstocks for biodiesel production (Hu et al., 2008; Taleb et al., 2015; Van Vooren et al., 2012; Kandilian et al., 2014).

Microalgal biodiesel has the potential to meet the global demand for transportation fuel, but this technology still needs to overcome many hurdles, before being deployed at large scale and becoming competitive in the fuel market (Hannon et al., 2010; Scott et al., 2010; Li et al., 2011; Rawat et al., 2013; Chisti, 2013). The challenges facing the profitable and sustainable microalgal 
biodiesel production have been previously discussed in numerous publications (Hannon et al., 2010; Scott et al., 2010; Li et al., 2011). The main challenge is to achieve tolerable outlay for a commercial production of microlalgal biodiesel (Chisti, 2008; Hannon et al., 2010). Based on estimated costs for 2009, one barrel of microalgal oil-based biofuels would cost $\$ 300-\$ 2600$ to produce using the current technologies, whereas one barrel of crude petroleum costs $\$ 40-\$ 120$ (Alabi et al., 2009). Note that, the cost of producing one barrel of microalgal biofuel can be reduced to $\$ 115$ when using biomass that contains $70 \%$ lipids by dry weight. Therefore, a cost reduction in oil rich biomass production is necessary for costeffective microalgal biodiesel production (Chisti, 2007). Consequently, improvements are necessary to overcome several obstacles facing upstream and downstream processes. These include finding favorable strains, optimizing culture conditions, improving biomass production procedures, and oil extraction techniques. Within this context, the strain selection is of primary importance, as its characteristics affect most significant steps of the development chain, such as lipids production, lipids extraction and their conversion to biodiesel. Some of the challenges include the wide biodiversity of microalgae and the dependency of their photosynthetic activity and especially their lipid metabolism on their cultivation conditions. Previously, Taleb et al., (2015) showed that TAG accumulation capacity cannot be the only criterion used to select the ideal strain. Many species are well known to accumulate large amount of neutral lipids and TAGs in nitrogen starvation conditions (Taleb et al., 2015). Though, this accumulation ability does not necessarily lead to large lipid productivity. It also does not guarantee easy recovery of the TAGs in downstream processing. Hence, supplemental criteria must be considered when selecting strains. Moreover, the produced microalgal biodiesel must meet certain quality standards. Desirable qualities are high oxidative stability, high Cetane number, and low melting point for improved viscosity and cold flow (Stansell et al., 2012). Note that these physical and chemical properties of biofuel are directly affected by the structure of the fatty acids such as the carbon chain length, the degree of unsaturation, and the branches of the carbon chain (Islam et al., 2013; Knothe, 2005). Highly saturated fatty acids provide a favorable cetane number and an excellent oxidative stability for biodiesel (Stansell et al., 2012). On the other hand, a very high percentage of saturated fatty acids and long carbon chains result in a poor cold flow viscosity. Thus, a balance between saturated and unsaturated fatty acids is necessary to achieve the desired properties. Finally, since TAGs are intracellular molecules, their extraction and recovery is necessary before their conversion into biodiesel. Cooney et al. (2011) and Halim et al. (2012) demonstrated that working on dry biomass must be avoided due to the large amount of energy consumed during the drying of biomass leading to a negative energy balance of the entire biodiesel production process. Therefore, wet TAG extraction processes must be used. This can be achieved, for example, by combining cell destruction technologies with TAG extraction methods that use organic solvents. Moreover, mechanical destruction is commonly used to recover intracellular molecules in a wet process. The disruption of microalgae cells by applying high-pressure homogenizers such as bead mills is one method to facilitate the solvent's access to intracellular TAG in wet environment. Consequently, the cell fragility or the mechanical resistance of the strain is an important criterion for the selection of promising strains for biodiesel production. Recently, Montalescot et al. (2015) investigated cell disruption efficacy of Nannochloropsis oculata and Porphyridium cruentum using high pressure bead milling in the range between 600 and 2700 bar. They found that cell disruption was at its maximum when the pressure applied was between 1500 and 2000 bar.

To summarize, a promising strain for biodiesel production must feature the following characteristics: i. A potential to accumulate large amount of TAGs under specific culture conditions like nitrogen starvation conditions.

ii. A capacity to sustain a high growth rate under stress conditions such as nutrient limitation in order to achieve high TAG productivity.

iii. Suitable fatty acid profile for biodiesel production with acceptable quality.

iv. The cells must be fragile enough for economical TAG recovery in wet environment.

Several studies have previously aimed to identify promising oleaginous microalgal strains (Rodolfi et al., 2009; Breuer et al., 2012; Gouveia and Oliveira, 2009; Hempel et al., 2012). Due to the different experimental conditions, a large variation in lipid and TAG productivity was reported, making it difficult to compare the data. Moreover, in most of these studies, the strains were characterized based on their total lipid content and productivity. Only few of those studies reported TAG content and lipid profiles despite the fact that the latter affects quality of the produced oil, or biodiesel, as previously discussed (Knothe, 2005, 2009). Moreover, to the best of our knowledge, no study has yet simultaneously investigated the TAG productivity of strains and their cell fragility despite the latter's importance in wet-biomass extraction process. For example, after an initial strain screening and cultivation condition optimization in lab conditions (Pruvost et al., 2011), Perrier et al., (2015) presented a successful transposition of the process to produce biodiesel using Nannochloropsis to an industrial facility. Lipid extraction was realized using solvent extraction on dry-biomass leading to the production of biodiesel that was tested in an automobile engine. However, life cycle analysis indicated the extensive energy consumption in the drying step and emphasized the need to utilize technologies that can minimize energy use. One method of achieving this is utilizing wet-biomass extraction techniques. The performance of the latter is strongly related on the selected strain and the process used. Therefore, a new selection criterion, namely, cell fragility was introduced in the current study in addition to more conventional criteria such as biomass and TAG productivity. Note that the Nannochloropsis oculata (Alphabiotech) strain used in Perrier et al. (2015) was one of the strains screened in the current study.

This study aims to present a novel approach to characterize freshwater and seawater strains of microalgae in identical and well-controlled conditions. It considers criteria most relevant for biodiesel production such as ease of cultivation, TAG productivity, TAG profiles, and cell fragility. The study also aims (i) to extend the pre-screening procedure developed in our previous work (Taleb et al., 2015) to five freshwater species of microalgae and (ii) to validate the performances of all fourteen strains in a larger $1 \mathrm{~L}$ flatpanel PBR.

\section{Materials and methods}

\subsection{Description of the overall screening process}

Fig. 1 illustrates the general approach of the screening procedure developed in this study. It consists of two steps: (1) a rapid pre-screening step and (2) a final validation step. The first step allows the adaptation of the different microalgae strains to the culture conditions encountered in photobioreactors. It also permits a fast screening of the strains by obtaining preliminary information regarding their behavior in PBRs, their biomass productivity, their cell fragility, their potential to accumulate TAG as well as their growth in nitrogen starvation conditions and subsequently their TAG productivity. Therefore, the first step leads to the selection of a number of promising strains that can be investigated in the 


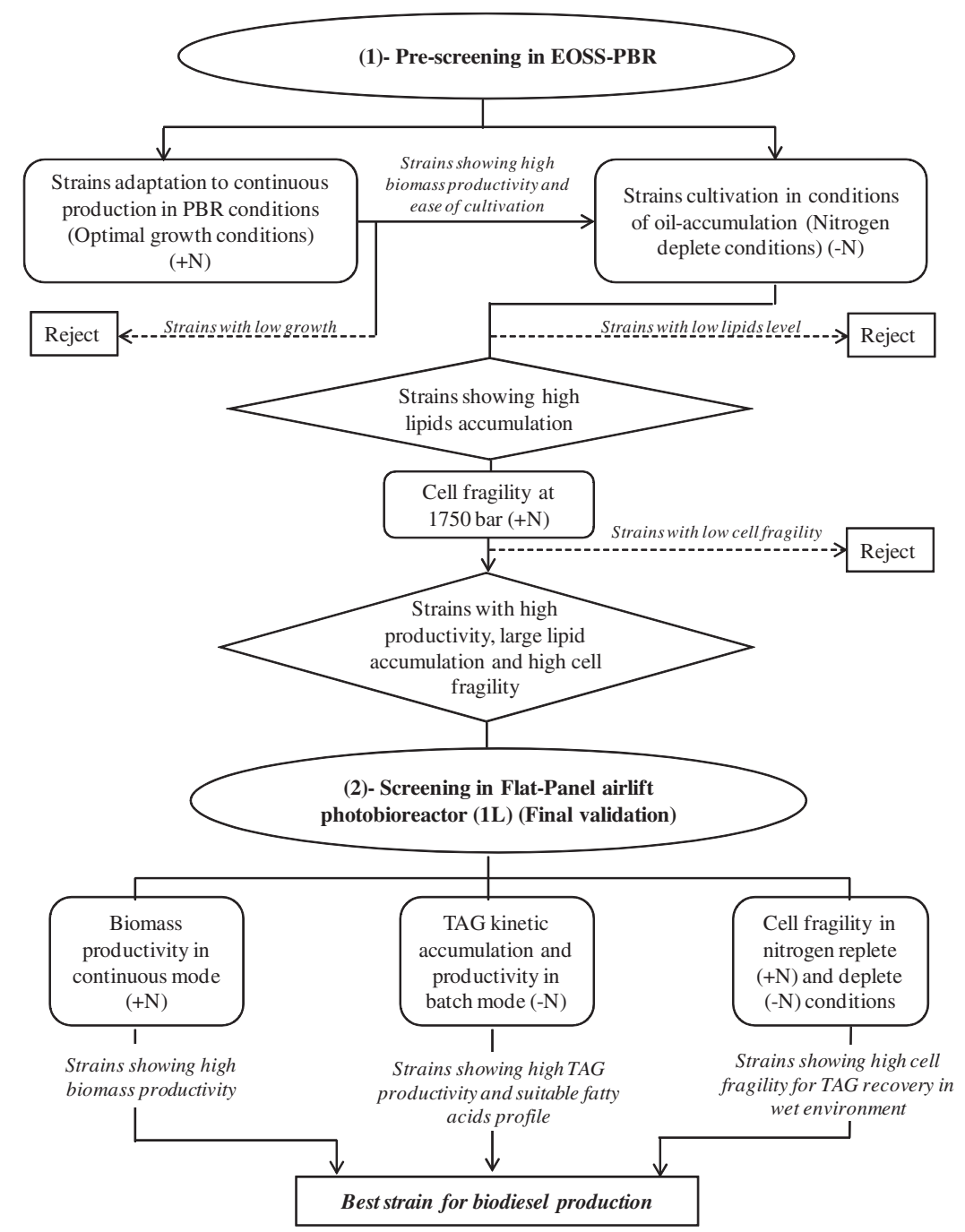

Fig. 1. Schematic illustrating the global screening procedure.

second step in fully controlled conditions in order to validate their performances.

\subsubsection{Step 1: Fast pre-screening in efficient overproducing screening system photobioreactors (EOSS-PBR)}

First, all the investigated strains were cultivated in the efficient overproducing screening system photobioreactor (EOSS-PBR), a purpose-designed cultivation system developed for screening microalgae in controlled and repeatable conditions. This PBR was described in more detail in our previous study (Taleb et al., 2015) and was used for the screening of nine seawater strains belonging to the Nannochloropsis genus. Here, the same cultivation conditions and the same operating modes are extended to five freshwater species of microalgae which are well-known for their potential to accumulate lipids. At this step, the fourteen strains were screened for their biomass productivity in nitrogen replete and deplete conditions, and for their TAG accumulation and productivity in nitrogen starvation conditions. Strain selection in Step 1 was carried out in three successive stages. The initial selection was based on the strain's biomass productivity in optimal conditions in semicontinuous mode. The strains that were trouble-free to grow in PBRs and showed high biomass productivity $\left(P_{X}>0.5 \mathrm{~kg} \mathrm{~m}^{-3} \mathrm{~d}^{-1}\right)$ were selected to be cultivated in nitrogen-free conditions in batch mode. Then, the strains showing TAG productivity $P_{\text {TAG }}$ higher than
$0.01 \mathrm{~kg} \mathrm{~m}^{-3} \mathrm{~d}^{-1}$ in nitrogen starvation conditions were selected to test their cell fragility.

2.1.2. Step 2: Depth screening in 1 L flat-panel PBR and final validation

This second step of the screening methodology entailed a detailed investigation of the promising strains identified through Step 1 . The selected strains were grown in a $1 \mathrm{~L}$ airlift-type flatpanel PBR with thickness of $3 \mathrm{~cm}$. The PBR was described in more detail in Pruvost et al. (2009) and Pruvost et al. (2011). Note that due to the larger PBR volume compared to EOSS-PBR, additional volume of samples could be drawn from the PBR in order to completely characterize the strains. Thus, it permitted the validation of the strains performances in an environment illustrative of the final industrial application. In fact, the low volume of EOSS-PBR $(30 \mathrm{ml})$ limited the number of times the culture could be sampled in Step 1 of the screening procedure and therefore it was not feasible to monitor the TAG accumulation kinetics of the strains during nitrogen deficiency. Indeed, the EOSS-PBR was especially designed for continuous cultivation to adapt strains to PBR growth conditions and characterize their biomass productivity in reliable conditions. In batch mode, the sampling volume was limited because of its small culture volume. Thus, it permitted us to determine the final concentration of TAG in the culture but not its temporal evolution. Moreover, the $1 \mathrm{~L}$ air-lift type PBR had a flat geometry which facilitated the determination of the strains' areal productivity and 
extrapolating it to other PBR geometries and/or volumes as demonstrated by Pruvost and Cornet (2012). Indeed, according to the authors areal productivity can be used to accurately and reliably compare strain performance across different cultivation vessels and PBR geometries given that they are grown under identical conditions such as $\mathrm{pH}$, irradiance, temperature, and nutrient availability. It can also be used to estimate the productivity of large scale microalgae farms used for biodiesel production, but not to accurately deduce productivities in outdoor PBRs since the effects of diurnal illumination and temperature variation are unaccounted for in the present study. Finally, it allows us to provide a first order comparison of microalgal biodiesel yields per hectare with those of other agricultural resources such as soybean.

\subsection{Strains and culture medium}

Fourteen microalgae strains were investigated in this study to validate the screening methodology described above. These strains were chosen based on their performances reported in the literature. They belonged to five different genus of microalgae (Chlorella, Parachlorella, Neochloris, Scenedesmus and Nannochloropsis) and 12 various species, which are well known for their industrial relevance. Their taxonomic classification is shown in Table 1.

Nine of the studied microalgae were marine eustigmatophyceae strains, and they belonged to five different species of Nannochloropsis (oculata, salina, granulata, gaditana and limnetica); while species of the two other strains (Nannochloropsis sp. CCMP531 and CCMP1779) were unknown. These seawater strains were prescreened and reviewed by Taleb et al., (2015) in EOSS-PBR. Here we validate their performance in a $1 \mathrm{~L}$ flat-panel PBR. The other five freshwater strains were Neochloris oleobundans, Chlorella vulgaris, Parachlorella kessleri, Scenedesmus obliquus, and Scenedesmus sp. UTEX 1589. The strains were obtained from four different collections, namely, the Culture Collection of Marine Phytoplankton (CCMP), the culture collection of algae at the University of Texas at Austin (UTEX), the Culture Collection of algae and protozoa (CCAP), and the Alphabiotech collection (Asserac, France). Table 2 shows the list of all the investigated strains along with their names, their species and their origin. All seawater strains were grown in artificial seawater with salinity of $25 \mathrm{~g} \mathrm{~L}^{-1}$ (Berges et al., 2001). They were enriched with modified Conway medium (3N3P) for nutrientreplete semi-continuous and continuous cultures, and nitrogenfree Conway medium for sudden nitrogen starvation batch cultures. Furthermore, the freshwater strains were cultivated in a modified bold basal medium (BBM) (Pruvost et al., 2009). In continuous and semi-continuous cultures, the strains were grown in light-limited growth conditions, i.e., the medium composition was adjusted to avoid any mineral limitation, so the growth was only limited by light (Pruvost et al., 2008). The temperature and the $\mathrm{pH}$ were respectively $25^{\circ} \mathrm{C}$ and 8 for all the experiments.

\subsection{Analytical methods and determination of strains features}

\subsubsection{Dry weight measurements and determination of biomass productivities}

Microalgae dry weight concentration $C_{X}$ was determined gravimetrically by filtering given culture volume through a pre-dried
Table 2

Names, species and culture collection origin of the fourteen strains tested in this study.

\begin{tabular}{lll}
\hline Strain full name & Culture collection & Environment \\
\hline Nannochloropsis oculata 525 & CCMP & Seawater \\
Nannochloropsis oculata Alphabiotech & Alphabiotech & Seawater \\
Nannochloropsis salina 537 & CCMP & Seawater \\
Nannochloropsis salina 538 & CCMP & Seawater \\
Nannochloropsis limnetica 505 & CCMP & Seawater \\
Nannochloropsis granulata 529 & CCMP & Seawater \\
Nannochloropsis gaditana 527 & CCMP & Seawater \\
Nannochloropsis sp. 1779 & CCMP & Seawater \\
Nannochloropsis sp. 531 & CCMP & Seawater \\
Scenedesmus obliquus 393 & UTEX & Freshwater \\
Scenedesmus sp. 1589 & UTEX & Freshwater \\
Neochloris oleobundans 1185 & UTEX & Freshwater \\
Chlorella vulgaris $211 / 19$ & CCAP & Freshwater \\
Parachlorella kessleri 2229 & UTEX & Freshwater \\
\hline
\end{tabular}

and pre-weighed glass-fiber filter (Whatman GF/F). The filters were dried for $24 \mathrm{~h}$ at $105^{\circ} \mathrm{C}$, cooled down in a desiccator for $10 \mathrm{~min}$ and then reweighed. Reported results are the arithmetic means of three measurements and the error bars correspond to the standard deviations. The average biomass concentration was then used to determine the volumetric and areal biomass productivities of all the investigated strains. For semi-continuous and continuous cultures, the volumetric biomass productivity was determined at steady-state by dividing the measured dry biomass concentration with the residence time of the microalgae $\tau$ in the PBR (Pruvost et al., 2008)

$P_{X}=D \cdot C_{X}=\frac{C_{X}}{\tau}$

The microalgae residence time $\tau$ (days) was fixed by the flow rate of fresh medium in the PBR and can be related to the dilution rate $D$ of the culture $\tau=\frac{1}{D}$. On the other hand, for the sudden starvation experiments carried out in batch mode, volumetric biomass productivity can be estimated as

$r_{X}=\frac{C_{X f-} C_{X i}}{\Delta t}$

where $C_{X i}$ and $C_{X f}$ are the initial and final biomass concentration of the culture, respectively, and $\Delta t$ (in days) corresponded to the duration of the batch culture. For the cultures grown in $1 \mathrm{~L}$ flat-panel PBR, daily areal productivity $S_{X}\left(\right.$ in $\mathrm{kg} \mathrm{m}^{-2}$ day $\left.^{-1}\right)$ was deduced from the volumetric biomass productivity $P_{X}\left(\right.$ in $\left.\mathrm{kg} \mathrm{m}^{-3} \mathrm{day}^{-1}\right)$ and the illuminated specific area $a_{s}\left(\mathrm{~m}^{-1}\right)$ of the PBR

$S_{X}=P_{X} \cdot \frac{V}{S}=\frac{P_{X}}{a_{S}}$

Here, $V\left(\mathrm{~m}^{3}\right)$ and $S\left(\mathrm{~m}^{2}\right)$ correspond to the volume and the surface area of the PBR, respectively. For the flat-plate PBR used in this study, the illuminated specific area can be estimated using the PBR thickness $e(\mathrm{~m})$ as $a_{s}=\frac{1}{e}$. Then, the areal productivity can be expressed as

$\boldsymbol{S}_{\boldsymbol{X}}=\boldsymbol{P}_{\boldsymbol{X}} \cdot e$

Table 1

Taxonomic classification of the five microalgae genus tested in this study.

\begin{tabular}{|c|c|c|c|c|}
\hline Genus & Division & Class & Order & Family \\
\hline Neochloris & Chlorophyta & Chlorophyceae & Chlorococcales & Chlorococcaceae \\
\hline Chlorella & Chlorophyta & Trebouxiophyceae & Chlorellales & Chlorellaceae \\
\hline Parachlorella & Chlorophyta & Trebouxiophyceae & Chlorellales & Chlorellaceae \\
\hline Scenedesmus & Chlorophyta & Chlorophyceae & Sphaeropleales & Scenedesmaceae \\
\hline Nannochloropsis & Heterokontophyta & Eustigmatophyceae & & Eustigmataceae \\
\hline
\end{tabular}




\subsubsection{Lipid analysis and determination of TAG productivities}

The total lipids were extracted from the dried biomass with 2:1 (v/v) organic solvent mixture of chloroform: methanol using Folch et al. (1957) and Bligh and Dyer (1959) extractions methods. Triglycerides were then separated from other lipid classes by solid-phase extraction (SPE). They were transesterified with methanol and their concentration as well as their fatty acid profile was determined by gas chromatography with a flame ionization detector (GC-FID). The extraction and separation methods were previously validated and reported in more detail by Van Vooren et al. (2012). Volumetric TAG productivity $P_{T A G}$ was calculated by multiplying the biomass production rate $P_{X}$ with the TAG concentration by dry weight $w_{\text {TAG }}$. Similarly, the areal TAG productivity $S_{T A G}$ was obtained by $S_{T A G}=P_{T A G} \cdot e$.

\subsubsection{High-pressure cell disruption and investigation of cell fragility}

Cell fragility was evaluated by measuring the fraction of disrupted cells after flowing a given culture volume in a high pressure disrupter TS series, 2.2-kW (Constant Systems Limited, Northants, UK). A more detailed description of the disrupter is available in Jubeau et al. (2013) and Montalescot et al. (2015). For each strain, $40 \mathrm{ml}$ of culture suspension was collected and passed through the disrupter in 4 cycles at a pressure of 1750 bar. Note that this pressure was chosen as the mean value of the optimal disruption pressure range 1500-2000 bar reported for $N$. oculata cells as previously mentioned (Montalescot et al., 2015). Note that the cell suspension was well mixed in the supply tank before disruption to insure a good homogeneity of the sample. For each strain, cell concentrations $N$ (in cells $/ \mathrm{ml}$ ) was determined under an optical microscope using Malassez counting-chamber before and after the culture grinding, and the percentage of disrupted cells was obtained by

$\%$ disruption $=\frac{N \text { after disruption }}{N \text { before disruption }} * 100$

\subsection{Strains cultivation in efficient overproducing screening system photobioreactors (EOSS-PBR) and shake flasks}

At the pre-screening step all the investigated strains were grown under optimal growth conditions in EOSS-PBR operating in semi-continuous mode with a dilution rate $D=0.24 \mathrm{day}^{-1}$ $\left(0.01 \mathrm{~h}^{-1}\right)$. All the cultures were exposed to an incident PFD of $150 \mu \mathrm{mol}_{\mathrm{h} v} / \mathrm{m}^{2} \mathrm{~s}^{-1}$. Their growth was evaluated by monitoring the culture cell concentration daily. The biomass productivity was determined by measuring the biomass concentration of each culture upon three consecutive days when the culture reached steady-state conditions. Strains with the largest biomass productivity were harvested and then re-suspended in nitrogen-free medium in a second EOSS-PBR to determine their TAG accumulation. Cultures were diluted to an initial biomass concentration $C_{X}=0.2$ $\mathrm{kg} \mathrm{m}^{-3}$. The lipid and TAG concentrations of nitrogen starved cultures were measured on the eleventh day of cultivation, which corresponded to the approximate duration necessary for the microorganisms to achieve their maximum TAG concentration (Van Vooren et al., 2012).

\subsection{Strains cultivation in $1 \mathrm{~L}$ airlift-type flat-panel PBR}

Microalgae were cultivated in optimal growth conditions in a $1 \mathrm{~L}$ airlift-type flat-panel PBR, $3 \mathrm{~cm}$ thick, exposed to an incident PFD of $150 \mu \mathrm{mol}_{\mathrm{h} v} \mathrm{~m}^{-2} \mathrm{~s}^{-1}$, and operating in continuous mode with a dilution rate $D=0.01 \mathrm{~h}^{-1}$. The harvest from optimally grown cultures was used to inoculate the $1 \mathrm{~L}$ flat-panel PBRs used for the sudden nitrogen starvation batch experiments. The same protocol as in the pre-screening step was followed here, i.e., all the sudden starvation experiments were carried out with an initial biomass concentration of $C_{X}=0.2 \mathrm{~kg} \mathrm{~m}^{-3}$ and an incident PFD of $250 \mu \mathrm{mol}_{\mathrm{h}^{-}}$ $v \mathrm{~m}^{-2} \mathrm{~S}^{-1}$. More information about this protocol can be found in Van Vooren et al. (2012), Kandilian et al. (2014) and Taleb et al. (2015). The culture's growth and their TAG accumulation kinetics were measured during the 11 days of cultuvation. Their cell fragility in nitrogen starvation conditions were also investigated on the eleventh day of the experiment.

For all experiments carried-out in either EOSS-PBR or in the $1 \mathrm{~L}$ flat panel air-lift, the $\mathrm{pH}$ was continuously and automatically regulated at 8.0 by automatic injection of pure $\mathrm{CO}_{2}$ when the $\mathrm{pH}$ rose above the set value. Similarly, the temperature was maintained at $25^{\circ} \mathrm{C}$ by ambient air flow. The PBRs were also injected with sterile air from the bottom in order to ensure good mixing and to keep the cells in suspension.

\section{Results and discussions}

\subsection{Pre-screening in EOSS-PBR and preliminary selection of promising strains}

\subsubsection{Stage 1: biomass productivity and ease of cultivation}

Table 3 summarizes the volumetric biomass productivity of all the investigated strains. A large variation was observed in the volumetric biomass productivity of the various strains ranging from $0.05 \mathrm{~kg} \mathrm{~m}^{-3} \mathrm{~d}^{-1}$ for $N$. oculata $\mathrm{AB}$ to $0.89 \mathrm{~kg} \mathrm{~m}^{-3} \mathrm{~d}^{-1}$ for $S$. obliquus UTEX393. Note that, this variation was not only observed between the different genuses but also between the different species of the same genus and even different strains of the same species. In our previous work (Taleb et al., 2015), we demonstrated a large variation between the different Nannochloropsis species where Nannochloropsis sp CCMP1779 featured 13 times larger biomass productivity compared to $N$. oculata $\mathrm{AB}$. Similar variation in the biomass productivity of freshwater species was also observed here (Table 3). Among the 14 screened strains, four seawater strains, namely, N. salina CCMP537, Nannochloropsis sp. CCMP531, N. gaditana CCMP527, and Nannochloropsis sp. CCMP1779, and four freshwater strains, namely, P. kessleri UTEX2229, Scenedesmus sp. UTEX1589, S. obliquus UTEX393, and C. vulgaris CCAP211/19 showed daily biomass productivity greater than or equal to $0.5 \mathrm{~kg} \mathrm{~m}^{-3} \mathrm{~d}^{-1}$. In addition, these strains were easy to cultivate in PBRs without hindrances such as cell settlement, biofilm, or floc formation.

\subsubsection{Stage 2: maximum TAG productivity}

As previously stated, TAG accumulation is not a sufficient criterion to choose the best strain for biodiesel production. Therefore, the strains selected at the previous stage were screened for their volumetric TAG productivity on the eleventh day of their respective batch nitrogen starvation cultures.

Table 3 shows the volumetric TAG productivity $P_{\text {TAG }}$ of the 8 species screened. The investigated strains showed a large variation in their ability to accumulate total lipids and TAGs, as well as in their biomass productivity in nitrogen starvation conditions. Indeed, among the 8 studied strains $N$. salina CCMP537, $N$. gaditana CCMP527, S. obliquus UTEX393, Scenedesmus sp. UTEX1589, and $P$. kessleri UTEX2229 exhibited volumetric TAG productivity $P_{\text {TAG }}$ larger than $0.01 \mathrm{~kg}_{\text {TAG }} \mathrm{m}^{-3} \mathrm{~d}^{-1}$. These five strains were then screened for their cell fragility.

\subsubsection{Stage 3: cell fragility}

Table 3 demonstrates that the strains showed significant discrepancy in their cell fragility. This variation may be related to the differences in the composition of the cells and the different 
Table 3

Global report of the pre-screening step. Volumetric biomass productivity $P_{X}$ and cell fragility in optimal growth conditions (+N) and volumetric TAG productivity in sudden nitrogen starvation conditions $(-\mathrm{N})$. Legend: $(+)$ strains were grown in EOSS-PBR without hindrances, $(++)$ strains were easy to cultivate. The best performing strains which were selected at this pre-screening step are marked in red.

\begin{tabular}{|c|c|c|c|c|}
\hline Strains & $\begin{array}{c}\text { Volumetric biomass } \\
\text { productivity }(+\mathrm{N}) \\
P_{X}\left(\mathrm{~kg} \cdot \mathrm{m}^{-3} \cdot \mathrm{d}^{-1}\right)\end{array}$ & $\begin{array}{c}\text { Ease of } \\
\text { cultivation }\end{array}$ & $\begin{array}{c}\text { Volumetric TAG } \\
\text { productivity }(-\mathrm{N}) \\
P_{\text {TAG }}\left(\mathrm{kg} \cdot \mathrm{m}^{-3} \cdot \mathrm{d}^{-1}\right)\end{array}$ & $\begin{array}{c}\text { Cell fragility } \\
\text { at } 1750 \text { bars }(+N) \\
(\% \text { of cells } \\
\text { disruption) } \\
\end{array}$ \\
\hline $\begin{array}{l}\text { N. oculata } \\
\text { CMP525 }\end{array}$ & 0.12 & + & - & - \\
\hline $\begin{array}{l}\text { N. salina } \\
\text { CCMP537 }\end{array}$ & $0.63 \pm 0.07$ & ++ & 0.018 & $58 \pm 3$ \\
\hline $\begin{array}{l}\text { N.salina } \\
\text { CCMP538 }\end{array}$ & $0.28 \pm 0.05$ & & - & - \\
\hline $\begin{array}{l}\text { N. sp. } \\
\text { CCMP531 }\end{array}$ & $0.5 \pm 0.16$ & + & 0.009 & - \\
\hline $\begin{array}{l}\text { N. sp. } \\
\text { CCMP1779 }\end{array}$ & $0.67 \pm 0.12$ & + & 0.004 & - \\
\hline $\begin{array}{l}\text { N. gaditana } \\
\text { CMP527 }\end{array}$ & $0.54 \pm 0.09$ & ++ & 0.013 & $81 \pm 5$ \\
\hline $\begin{array}{l}\text { N. granulata } \\
\text { CCMP529 }\end{array}$ & $0.19 \pm 0.05$ & - & - & - \\
\hline $\begin{array}{l}\text { N. limnetica } \\
\text { CCMP } 505\end{array}$ & $0.41 \pm 0.07$ & + & - & - \\
\hline N.o AB & 0.05 & + & - & - \\
\hline $\begin{array}{l}\text { S. obliquus } \\
\text { UTEX393 }\end{array}$ & $0.89 \pm 0.05$ & ++ & 0.012 & $73 \pm 7$ \\
\hline $\begin{array}{l}\text { S. sp. } \\
\text { UTEX1589 }\end{array}$ & $0.79 \pm 0.1$ & ++ & 0.02 & $41 \pm 6$ \\
\hline $\begin{array}{l}\text { P. kessleri } \\
\text { UTEX2229 }\end{array}$ & $0.67 \pm 0.07$ & ++ & 0.016 & $90 \pm 4$ \\
\hline $\begin{array}{l}\text { N. oleobundans } \\
\text { UTEX1185 }\end{array}$ & $0.47 \pm 0.06$ & + & - & - \\
\hline $\begin{array}{l}\text { C. vulgaris } \\
\text { CCAP211/19 }\end{array}$ & $0.66 \pm 0.22$ & ++ & 0.0002 & - \\
\hline
\end{tabular}

physiochemical properties of each strain's cell wall. The strains were then classified into three categories. Fragile strains included P. kessleri UTEX2229 and N. gaditana CCMP527 showing cells disruption rate larger than $80 \%$. Medium fragility strains such as $N$. salina CCMP537 (58.1\%) and S. obliquus UTEX393 (73\%) featuring cell fragility greater than $50 \%$. Finally, the most resilient strain was Scenedesmus sp. UTEX1589 featuring $41 \%$ cells disruption fraction. Thus, all the strains screened in this stage except for Scenedesmus sp. UTEX1589 showed promising cell fragility for wet TAG extraction. The four strains $P$. kessleri UTEX2229, $N$. gaditana CCMP527, $N$. salina CCMP537, and S. obliquus UTEX393 were selected for investigation in Step 2 of the screening procedure, i.e., the validation step.

\subsection{Validation of strains performances in 1 L flat-panel PBR}

\subsubsection{Validation of growth performances in nitrogen replete and deplete conditions}

Table 4 shows the volumetric and areal biomass productivity of the four selected strains grown in photo-limited conditions in continuous mode at steady-state. Moreover, Fig. 2 shows their growth kinetics over 11 days of their cultivation in sudden nitrogen starvation conditions. Cultures of $N$. salina CCMP537, N. gaditana CCMP527 and P. kessleri UTEX2229 featured steady-state volumetric biomass productivities $P_{X}$ of $0.317,0.386$, and $0.364 \mathrm{~kg} \mathrm{~m}^{-3} \mathrm{~d}^{-1}$, respectively. These corresponded to areal biomass productivities $S_{X}$ of $9.51 \times 10^{-3}, 11.6 \times 10^{-3}$, and $10.9 \times 10^{-3} \mathrm{~kg} \mathrm{~m}^{-2} \mathrm{~d}^{-1}$, respectively. In addition, S. obliquus UTEX393 featured the largest areal biomass productivity equaling to $18.8 \times 10^{-3} \mathrm{~kg} \mathrm{~m}^{-2} \mathrm{~d}^{-1}$ The latter was 1.7 times larger than that of P. kessleri UTEX2229, the strain featuring the second largest biomass productivity.

On the other hand, these four strains behaved differently during sudden nitrogen starvation experiments. As seen in Fig. 2, their

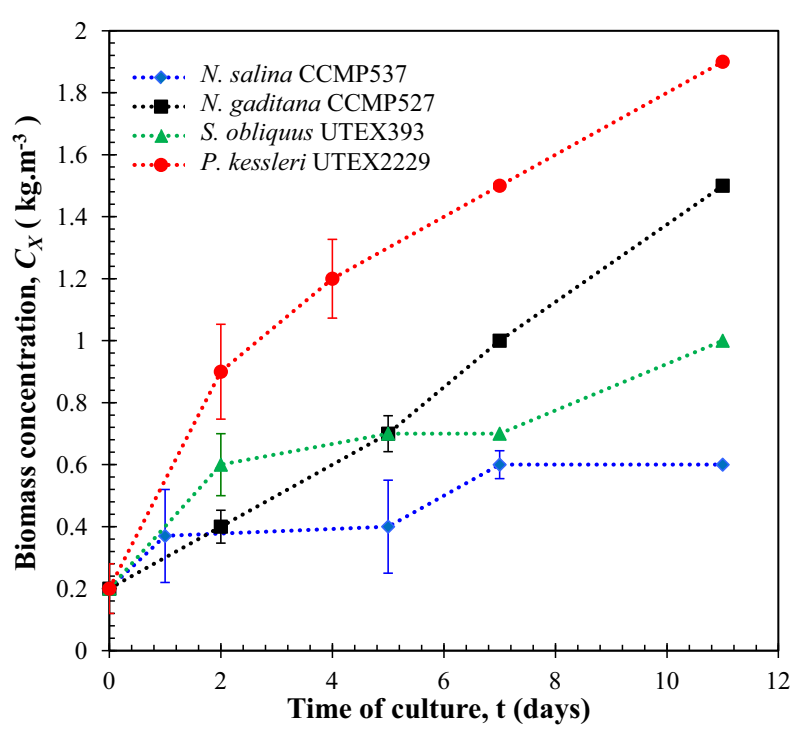

Fig. 2. Growth Kinetics characterization of the four strains grown under sudden nitrogen starvation $(-\mathrm{N})$ in $1 \mathrm{~L}$ flat-panel PBR exposed to an incident PFD of $250 \mu \mathrm{mol}_{\mathrm{hv}} / \mathrm{m}^{2} \mathrm{~s}$.

growth kinetics was different despite the identical culture conditions. For example, N. salina CCMP537 featured the lowest biomass growth rate in nitrogen starvation conditions. Its initial biomass concentration of $0.2 \mathrm{~kg} \mathrm{~m}^{-3}$ increased to only $0.6 \mathrm{~kg} \mathrm{~m}^{-3}$ on the seventh day of cultivation, and remained constant thereafter. By contrast, $N$. gaditana CCMP527, belonging to the same genus, had much larger biomass growth rate in nitrogen starvation conditions. It approximately had a constant growth rate through the duration 
of the batch culture, increasing its biomass concentration from an initial value of $0.2 \mathrm{~kg} \mathrm{~m}^{-3}$ to $1.5 \mathrm{~kg} \mathrm{~m}^{-3}$.

The freshwater strain P. kessleri UTEX2229 had the largest biomass productivity in nitrogen starvation conditions. Indeed, its biomass concentration increased tenfold during the eleven days of cultivation. Such large growth rate is not typical for microalgae during nitrogen starved conditions. We speculate that this may have been due to the strain's naturally high protein content, around $60 \%$ DW in optimal conditions (Taleb, 2015), acting as nitrogen reserve when the cells were suspended in nitrogen-free medium. Then, it is possible for the cells to display large growth rates under nitrogen starvation due to the remobilization of the stored nitrogen sources (Van Vooren et al., 2012; Onodera and Ohsumi, 2005). It may also be due to the cells' large pigment concentration resulting in large rate of light absorption. Indeed, Cornet and Dussap (2009) have shown that biomass productivity can be directly correlated to the rate of light absorption by the cells. Finally, S. obliquus UTEX393 showed the highest biomass productivity in optimal conditions while it had the lowest biomass productivity in nitrogen starvation conditions. This highlights again the dependence of the strains performances on the culture conditions and emphasizes the importance of developing specialized screening procedures for different applications and growth conditions.

\subsubsection{Validation of the TAG production performances for the selected} strains

Fig. 3 shows the TAG accumulation kinetics of the four selected strains over eleven days of their cultivation in nitrogen deplete conditions. In all strains, TAG accumulation was observed immediately after cell re-suspension in nitrogen-free medium (Fig. 3). The seawater strains $N$. gaditana CCMP527 and N. salina CCMP537 featured the highest TAG accumulation among all the investigated strains. Indeed, both species had nearly identical temporal evolution of intracellular TAG content. The latter increased linearly from $3 \% \mathrm{DW}$ at the beginning of the culture to $50 \% \mathrm{DW}$ on the seventh day of cultivation for N. gaditana CCMP527 and from 12\% DW to $59 \%$ DW for N. salina CCMP537. Subsequently, their TAG accumulation rate decreased until the end of the experiment (Fig. 3). On the other hand, the freshwater strains P. kessleri UTEX2229 and S. obliquus UTEX393 accumulated relatively smaller amounts of TAG by dry weight compared to the seawater strains. Fig. 3 illustrates that the TAG concentration of P. kessleri UTEX2229 sharply increased

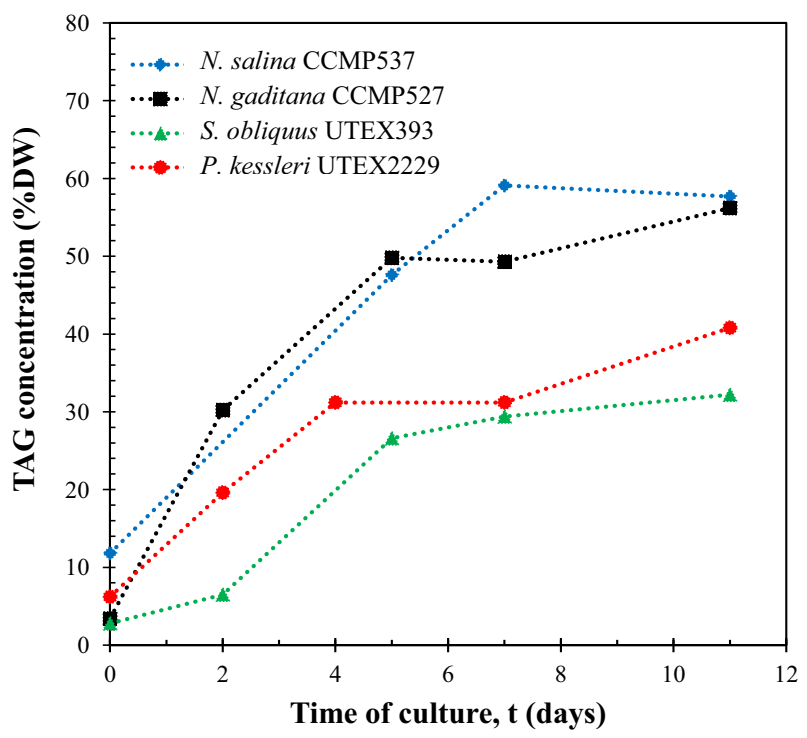

Fig. 3. TAG accumulation kinetics of the four strains grown under sudden nitrogen starvation $(-\mathrm{N})$ in $1 \mathrm{~L}$ flat-panel PBR exposed to an incident PFD of $250 \mu \mathrm{mol} / \mathrm{hv} / \mathrm{m}^{2} \mathrm{~s}$. from $6 \% \mathrm{DW}$ at the beginning of the starvation to $31 \% \mathrm{DW}$ on the fourth day of cultivation while $S$. obliquus had an initial TAG concentration of $3 \% \mathrm{DW}$ and accumulated $27 \% \mathrm{DW}$ by the fifth day of cultivation. Subsequently, the TAG accumulation rate decreased for both strains and no significant increase in TAG concentration was observed for S. obliquus UTEX393 until the end of the cultivation. By contrast, the TAG concentration of P. kessleri UTEX2229 reached its maximum value of $40 \%$ DW on the eleventh day of the cultivation (Fig. 3).

Fig. 4 shows the temporal evolution of TAG productivity by the four investigated strains. Here, P. kessleri UTEX229 culture featured the largest TAG productivity among the screened strains with a maximum areal productivity $S_{\text {TAG }}$ of $2.7 \times 10^{-3} \mathrm{~kg} \mathrm{~m}^{-2} \mathrm{~d}^{-1}$ occurring on the fourth day of cultivation. Its TAG productivity decreased to $2 \times 10^{-3} \mathrm{~kg} \mathrm{~m}^{-2} \mathrm{~d}^{-1}$ on the seventh day of cultivation and remained approximately constant until the end. Note that $P$. kessleri UTEX2229 featured lower TAG concentration by dry weight compared to the Nannochloropsis strains but its higher TAG productivity was due to its higher biomass production rate during nitrogen starvation (Fig. 2). On the other hand, the $S$. obliquus UTEX393 culture had the lowest TAG productivity reaching maximum $S_{\text {TAG }}$ of $1 \times 10^{-3} \mathrm{~kg} \mathrm{~m}^{-2} \mathrm{~d}^{-1}$ on the fifth day of cultivation. Its TAG productivity decreased to $0.86 \times 10^{-3} \mathrm{~kg} \mathrm{~m}^{-2} \mathrm{~d}^{-1}$ on the seventh day of cultivation and remained constant until the end. By contrast, TAG productivity of Nannochloropsis strains had different temporal evolution compared to the freshwater strains. For example, the TAG productivity of $N$. gaditana CCMP527 sharply increased from $0.21 \times 10^{-3}$ to $1.8 \times 10^{-3} \mathrm{~kg} \mathrm{~m}^{-2} \mathrm{~d}^{-1}$ during the first two days of nitrogen starvation and it reached its maximum value of $2.28 \times 10^{-3} \mathrm{~kg} \mathrm{~m}^{-2} \mathrm{~d}^{-1}$ on the eleventh day of cultivation. However, $N$. salina CCMP537 had lower TAG productivity than $N$. gaditana CCMP527 since it had smaller biomass productivity in nitrogen starvation conditions (see Fig. 2). Its peak TAG productivity $S_{\text {TAG }}$ was equal to $1.42 \times 10^{-3} \mathrm{~kg} \mathrm{~m}^{-2} \mathrm{~d}^{-1}$ and occurred on the seventh day of cultivation. Thereafter, its TAG productivity decreased to $0.88 \times 10^{-3} \mathrm{~kg} \mathrm{~m}^{-2} \mathrm{~d}^{-1}$ and remained constant until the end of the experiment.

\subsubsection{Characterization of fatty acid profiles and their suitability for biodiesel applications}

The complete fatty acids profiles of the lipids contained in Nannochloropsis strains were reported in a previous publication (Taleb

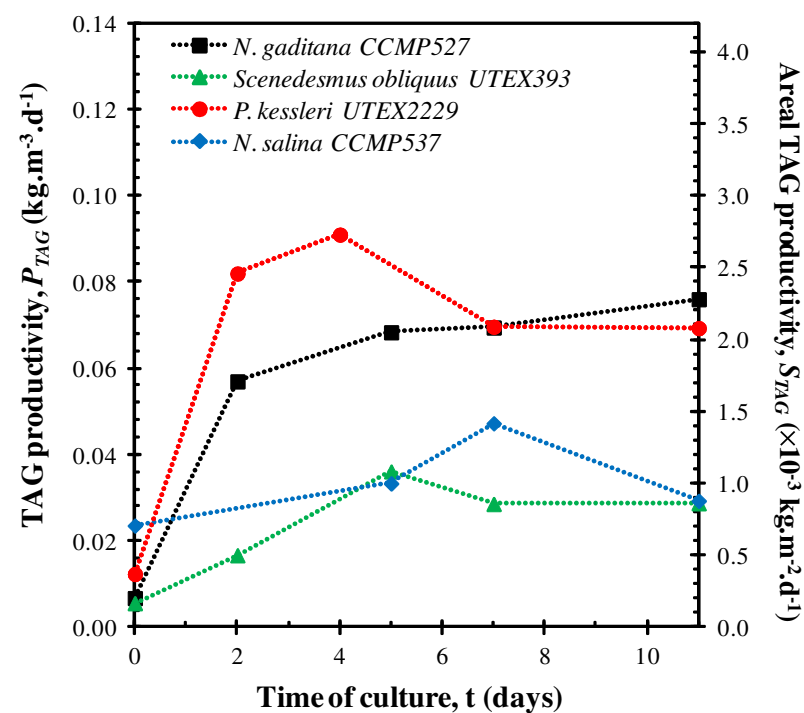

Fig. 4. Time evolution of the volumetric and areal TAG productivity of the four strains grown under sudden nitrogen starvation $(-\mathrm{N})$ in $1 \mathrm{~L}$ flat-panel PBR exposed to an incident PFD of $250 \mu \mathrm{mol}_{\mathrm{hv}} / \mathrm{m}^{2} \mathrm{~s}$. 
Table 4

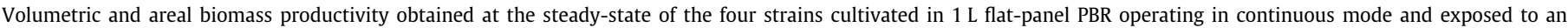
incident PFD of $150 \mu \mathrm{mol}_{\mathrm{hv}} / \mathrm{m}^{2} \mathrm{~s}$.

\begin{tabular}{|c|c|c|c|}
\hline Strains & Volumetric biomass productivity $P_{X}\left(\mathrm{~kg} \mathrm{~m}^{-3} \mathrm{~d}^{-1}\right)$ & Areal biomass productivity $S_{X}\left(\times 10^{-3} \mathrm{~kg} \mathrm{~m}^{-2} \mathrm{~d}^{-1}\right)$ & Confidence interval (\%) \\
\hline N. salina CCMP537 & 0.317 & 9.51 & 93 \\
\hline N.gaditana CMP527 & 0.386 & 11.58 & 92 \\
\hline P. kessleri UTEX2229 & 0.364 & 10.92 & 98 \\
\hline S. obliquus UTEX393 & 0.627 & 18.81 & 99.5 \\
\hline
\end{tabular}

A

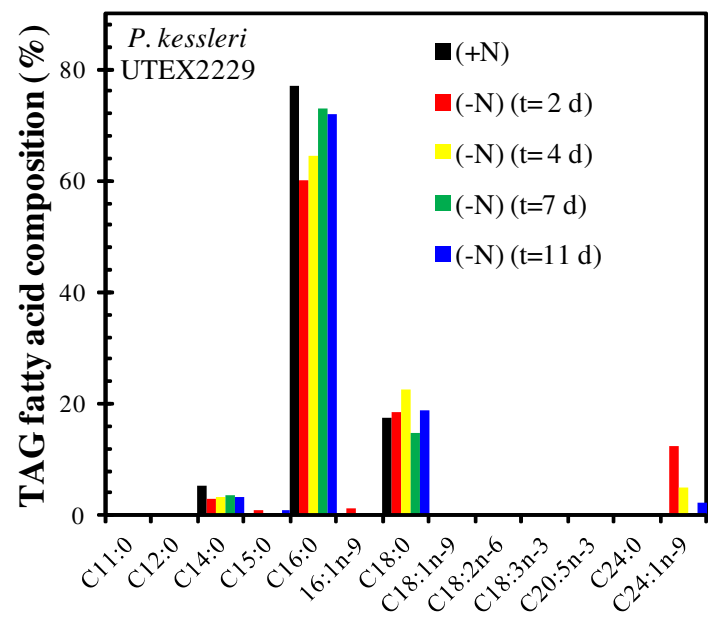

B

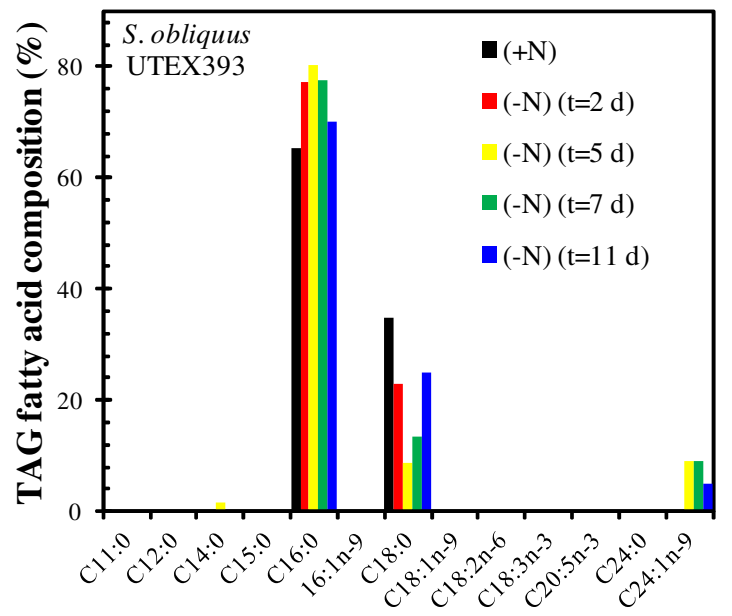

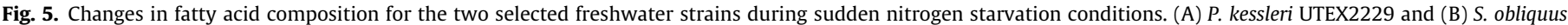
UTEX393.

et al., 2015). Here, the lipid profiles of only triacylglycerol fatty acids are reported as they are the most suitable feedstock for biodiesel production and they have the most effect on fuel properties. As previously reported (Taleb et al., 2015), Nannochloropsis strains showed considerable variations in their fatty acid compositions in both nitrogen-replete and deplete conditions. In addition, $N$. salina CCMP537 and N. gaditana CCMP527 presented lipid profiles most suitable for biodiesel production. Under nitrogen starvation conditions, their fatty acid lipid profiles were mostly composed of saturated palmitic acid (C16:0) and the monounsaturated palmitoleic acid (C16:1n-9). Other saturated and unsaturated fatty acids were also found such as myristic acid (C14:0), stearic acid (C18:0), oleic acid (C18:1n-9), and linoleic acid (C18:2n-6). Compared to normal growth conditions, very low amounts of polyunsaturated fatty acids such as the linolenic acid (C18:3n-3), eicosapentaenoic acid (C20:5n-3) and arachidonic acid (C20:4n-6) were detected, making the produced lipids suitable for biodiesel production.

Fig. 5 shows the TAG profiles of P. kessleri UTEX2229 and S. obliquus UTEX393 grown under optimal and nitrogen starvation conditions. It illustrates that under optimal growth conditions TAG molecules were mostly composed of the saturated palmitic acid (16:0) and stearic acid (18:0). Conversely, neither monounsaturated nor poly-unsaturated fatty acids were detected in these conditions. As previously reported by Van vooren et al. (2012), no significant variations were observed in fatty acids composition of TAG when comparing nitrogen deprived and nitrogenreplete cultures. In fact, Fig. $5 \mathrm{~A}$ illustrates that the main difference between nitrogen starved $P$. kessleri UTEX2229 culture and the optimally grown one was the decrease in palmitic acid (C16:0) and the increase of stearic acid (C18:0) from the start of the culture and up to the fourth day of starvation. Thereafter, C16:0 increased and C18:0 decreased simultaneously. By contrast, S. obliquus UTEX393 showed a different evolution of fatty acid profile in nitrogen starvation conditions. As shown by Fig. 5B, compared to nitrogen replete conditions, a simultaneous increase of $\mathrm{C} 16: 0$ and decrease of C18:0 were detected until the fifth day of the culture. Afterwards, palmitic acid (C16:0) decreased whereas stearic acid (C18:0) increased until the end of the experiment. These observations suggest that palmitic acid was the precursor of stearic acid (C18:0) formation through an elongation reaction catalyzed by ketoacyl-ACP Synthase II (KAS II) (Wu et al., 1994). In addition, the monounsaturated nervonic acid (C24:1n-9) appeared on the second day of nitrogen starvation for P. kessleri UTEX2229, and on the seventh day for S. obliquus UTEX393. It decreased thereafter until the end of the culture. In summary, the TAG produced by these two freshwater strains featured a high saturation degree which can lead to the production of biodiesel with high oxidation stability, high Cetane number, and high melting point resulting in poor cold flow properties and high fuel viscosity (Stansell et al., 2012).

\subsubsection{Investigation of the cell fragility in nitrogen replete and deplete conditions}

The cell fragility of the four selected strains was validated in optimal growth conditions in continuous cultures when they achieved steady-state conditions. Fig. 6 shows that the strains showed cell fragility close to those found at the pre-screening step with the exception of S. obliquus UTEX393. The latter had significantly lower cell disruption fraction in the validation stage. Similarly, strains cell fragility were determined on the eleventh day of sudden nitrogen starvation cultures. Fig. 6 illustrates that culture conditions did not have significant impact on the cell fragility of the microalgae with the exception of S. obliquus UTEX393. The latter was more resilient in nitrogen deplete conditions as indicated by the low cell disruption rate. The validation step here confirmed results in the pre-screening stage indicating that $N$. gaditana 
Table 5

General comparison of the performances of the four selected strains investigated in this study to those reported in the literature and belong to the same species.

\begin{tabular}{|c|c|c|c|c|c|c|}
\hline Strains & Culture conditions & $\begin{array}{l}\text { Total lipid } \\
\text { Content } \\
\text { (\% DW) }\end{array}$ & $\begin{array}{l}\text { TAG } \\
\text { content } \\
(\% \text { DW) }\end{array}$ & $\begin{array}{l}\text { Volumetric/areal total lipid } \\
\text { productivity }\left(\mathrm{kg} \mathrm{m}^{-3} \mathrm{~d}^{-1} /\right. \\
\left.10^{-3} \mathrm{~kg} \mathrm{~m}^{-2} \mathrm{~d}^{-1}\right)\end{array}$ & $\begin{array}{l}\text { Volumetric/ areal TAG } \\
\text { productivity }\left(\mathrm{kg} \mathrm{m}^{-3} \mathrm{~d}^{-1} /\right. \\
\left.10^{-3} \mathrm{~kg} \mathrm{~m}^{-2} \mathrm{~d}^{-1}\right)\end{array}$ & References \\
\hline S. obliquus UTEX393 & $\begin{array}{l}1 \mathrm{~L} \text { flat panel PBR (batch) }(-\mathrm{N}) \mathrm{pH}=8, \mathrm{~T}=25^{\circ} \mathrm{C}, \\
q_{0}=250 \mu \mathrm{mol} \mathrm{m}^{-2} \mathrm{~s}^{-1}\end{array}$ & 38.5 & 32 & $0.038 / 1.14$ & $0.036 / 1.08$ & Present study \\
\hline P. kessleri UTEX2229 & $\begin{array}{l}1 \mathrm{~L} \text { flat panel PBR (batch) }(-\mathrm{N}) \mathrm{pH}=8, \mathrm{~T}=25^{\circ} \mathrm{C} \text {, } \\
q_{0}=250 \mu \mathrm{mol} \mathrm{m}{ }^{-2} \mathrm{~s}^{-1}\end{array}$ & 65 & 46 & $0.115 / 3.45$ & $0.091 / 2.73$ & Present study \\
\hline N. gaditana CCMP527 & $\begin{array}{l}1 \mathrm{~L} \text { flat panel PBR (batch) }(-\mathrm{N}) \mathrm{pH}=8, \mathrm{~T}=25^{\circ} \mathrm{C} \text {, } \\
q_{0}=250 \mu \mathrm{mol} \mathrm{m}^{-2} \mathrm{~s}^{-1}\end{array}$ & 58 & 56 & $0.080 / 2.4$ & $0.076 / 2.28$ & Present study \\
\hline N. salina CCMP537 & $\begin{array}{l}1 \mathrm{~L} \text { flat panel PBR (batch) }(-\mathrm{N}) \mathrm{pH}=8, \mathrm{~T}=25^{\circ} \mathrm{C} \text {, } \\
q_{0}=250 \mu \mathrm{mol} \mathrm{m}^{-2} \mathrm{~s}^{-1}\end{array}$ & 63 & 59 & $0.049 / 1.47$ & $0.047 / 1.41$ & Present study \\
\hline Scenedesmus obliquus CNW-N & $\begin{array}{l}\text { Glass tank }(1 \mathrm{~L})(\text { batch })(-\mathrm{N})(5 \text { days }) \mathrm{pH}=6.2 \text {, } \\
\mathrm{T}=28^{\circ} \mathrm{C}, q_{0}=140 \mu \mathrm{mol} \mathrm{m}{ }^{-2} \mathrm{~s}^{-1} 2.5 \% \mathrm{CO}_{2}\end{array}$ & 22.4 & $-1-$ & $0.140 /-$ & $-1-$ & Ho et al. (2012) \\
\hline Scenedesmus obliquus UTEX 393 & $\begin{array}{l}\text { Airlift flat panel PBR }(\mathrm{V}=380 \mathrm{ml})(\mathrm{batch})(-\mathrm{N}) \\
\mathrm{pH}=7, \mathrm{~T}=27.5^{\circ} \mathrm{C}, q_{0}=500 \mu \mathrm{mol} \mathrm{m}^{-2} \mathrm{~s}^{-1}\end{array}$ & $30-45$ & $30-40$ & $-1-$ & $-1-$ & Breuer et al. (2013) \\
\hline Scenedesmus obliquus UTEX 393 & $\begin{array}{l}\text { Flasks }(250 \mathrm{ml})(\text { batch })(-\mathrm{N})(14 \text { days }) \mathrm{T}=25^{\circ} \mathrm{C} \\
q_{0}=150 \mu \mathrm{mol} \mathrm{m}^{-2} \mathrm{~s}^{-1}\end{array}$ & $-1-$ & $-1-$ & $-1-$ & 0.322 & Breuer et al., (2012) \\
\hline N. gaditana CCAP $849 / 5$ & Flasks (batch)(-N) $\mathrm{T}=23^{\circ} \mathrm{C}, q_{0}=100 \mu \mathrm{mol} \mathrm{m}^{-2} \mathrm{~s}^{-1}$ & $-1-$ & 38 & $-1-$ & $-1-$ & $\begin{array}{l}\text { Simionato et al. } \\
\text { (2013) }\end{array}$ \\
\hline N. salina (GSBSTICHO) & $\begin{array}{l}\text { Glass tubes }(500 \mathrm{ml})(-\mathrm{N}) \mathrm{pH}=7, \mathrm{~T}=28^{\circ} \mathrm{C} \text {, } \\
q_{0}=175 \mu \mathrm{mol} \mathrm{m}^{-2} \mathrm{~s}^{-1}\end{array}$ & 25 & $-1-$ & $-1-$ & $-1-$ & Boussiba et al. (1987) \\
\hline N. occulata Alphabiotech & $\begin{array}{l}1 \text { L flat panel PBR (batch) }(-\mathrm{N}) \mathrm{pH}=8, \mathrm{~T}=25^{\circ} \mathrm{C}, \\
q_{0}=250 \mu \mathrm{mol} \mathrm{m}^{-2} \mathrm{~s}^{-1}\end{array}$ & 50 & 43 & $0.09 / 2.7$ & $0.086 / 2.6$ & $\begin{array}{l}\text { Van Vooren et al., } \\
\text { (2012) }\end{array}$ \\
\hline P. kessleri CCALA 255 & $\begin{array}{l}\text { Tubes }(50 \mathrm{ml})(\mathrm{batch})(-\mathrm{N}) \mathrm{pH}=8, \mathrm{~T}=28^{\circ} \mathrm{C} \\
q_{0}=500 \mu \mathrm{mol} \mathrm{m}^{-2} \mathrm{~s}^{-1}\end{array}$ & 51 & $-1-$ & $-1-$ & $-1-$ & Přibyl et al., (2012) \\
\hline P. kessleri CCALA 251 & $\begin{array}{l}\text { Tubes }(50 \mathrm{ml})(\text { batch })(-\mathrm{N}) \mathrm{pH}=8, \mathrm{~T}=28^{\circ} \mathrm{C} \\
q_{0}=500 \mu \mathrm{mol} \mathrm{m}^{-2} \mathrm{~s}^{-1}\end{array}$ & 50.8 & $-1-$ & $-1-$ & $-1-$ & Přibyl et al., (2012) \\
\hline P. kessleri CCALA 253 & $\begin{array}{l}\text { Tubes }(50 \mathrm{ml})(\text { batch })(-\mathrm{N}) \mathrm{pH}=8, \mathrm{~T}=28^{\circ} \mathrm{C} \text {, } \\
q_{0}=500 \mu \mathrm{mol} \mathrm{m}^{-2} \mathrm{~s}^{-1}\end{array}$ & 40.76 & $-1-$ & $-1-$ & $-1-$ & Přibyl et al., (2012) \\
\hline Chlorella sp. F\&M-M48 & $\begin{array}{l}\text { Glass bubbled tubes }(0.6 \mathrm{~L})(\text { batch })(-\mathrm{N}) \mathrm{pH}=7.5- \\
8.1, \mathrm{~T}=25^{\circ} \mathrm{C}^{2}, q_{0}=200 \mu \mathrm{mol} \mathrm{m} \mathrm{s}{ }^{-1}\end{array}$ & 30 & $-1-$ & 0.120 & $-1-$ & Rodolfi et al., (2009) \\
\hline Scenedesmus sp. DM & $\begin{array}{l}\text { Glass bubbled tubes }(0.6 \mathrm{~L})(\mathrm{batch})(-\mathrm{N}) \mathrm{pH}=7.5- \\
8.1, \mathrm{~T}=25^{\circ} \mathrm{C}, q_{0}=200 \mu \mathrm{mol} \mathrm{m}^{-2} \mathrm{~s}^{-1}\end{array}$ & 20 & $-1-$ & 0.108 & $-1-$ & Rodolfi et al., (2009) \\
\hline Nannochloropsis sp. F\&M-M24 & $\begin{array}{l}\text { Glass bubbled tubes }(0.6 \mathrm{~L})(\text { batch })(-\mathrm{N}) \mathrm{pH}=7.5 \\
-8.1, \mathrm{~T}=25^{\circ} \mathrm{C}, q_{0}=200 \mu \mathrm{mol} \mathrm{m}^{-2} \mathrm{~s}^{-1}\end{array}$ & 60 & $-1-$ & 0.36 & $-1-$ & Rodolfi et al., (2009) \\
\hline $\begin{array}{l}\text { Nannochloropsis sp. (university } \\
\text { of Hawaii) culture collection }\end{array}$ & $\begin{array}{l}\text { Airlift PBR ( } 3.2 \text { L) Batch nitrogen limitation } \\
\text { (14 days) }\end{array}$ & 35 & $-1-$ & $-1-$ & 0.063 & Griffiths et al., (2012) \\
\hline $\begin{array}{l}\text { Scenedesmus Sp (olate, Upington, } \\
\text { South Africa) }\end{array}$ & $\begin{array}{l}\text { Airlift PBR ( } 3.2 \mathrm{~L} \text { ) Batch nitrogen limitation } \\
\text { (14 days) }\end{array}$ & 43 & $-1-$ & $-1-$ & $-1-$ & Griffiths et al., (2012) \\
\hline Nannochloropsis sp. & $\begin{array}{l}\text { Poly-ethylene bags with bubbling air } \\
q_{0}=150 \mu \mathrm{mol} \mathrm{m}^{-2} \mathrm{~s}^{-1}\end{array}$ & 28.7 & $-1-$ & $-1-$ & 0.026 & $\begin{array}{l}\text { Gouveia and Oliveira } \\
\text { (2009) }\end{array}$ \\
\hline $\begin{array}{l}\text { Neochloris oleabundans } \\
\text { UTEX1185 }\end{array}$ & $\begin{array}{l}\text { Poly-ethylene bags with bubbling air } \\
q_{0}=200 \mu \mathrm{mol} \mathrm{m}^{-2} \mathrm{~s}^{-1}\end{array}$ & 29 & $-1-$ & $-1-$ & 0.026 & $\begin{array}{l}\text { Gouveia and Oliveira } \\
\text { (2009) }\end{array}$ \\
\hline
\end{tabular}




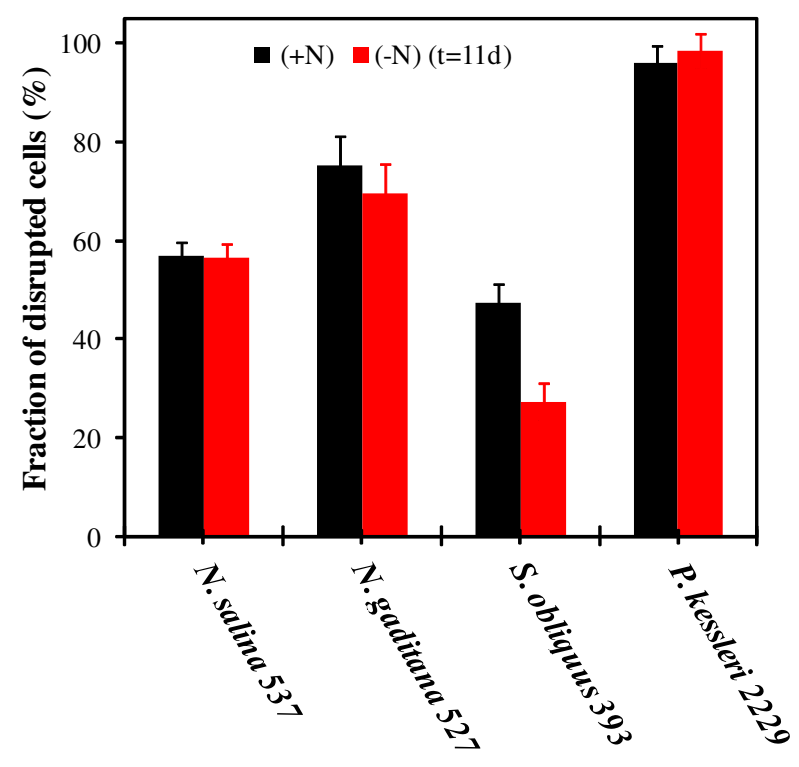

Fig. 6. Validation of the cell fragility at the steady-state in optimal growth conditions $(+\mathrm{N})$ for the four selected strains and investigation of their cell fragility at the eleventh day of the sudden nitrogen starvation experiments $(-\mathrm{N})$.

CCMP527 and P. kessleri UTEX2229 were the most fragile strains, both in nitrogen-replete and nitrogen starved conditions, when disrupted at 1750 bar. These presented promising results for TAG recovery in a wet environment. Note that, these two strains also featured the largest TAG areal productivities $S_{T A G}$ and also had suitable TAG profiles for biodiesel application.

\subsection{Final selection and performances comparison}

The strains N. gaditana CCMP527 and P. kessleri UTEX2229 were selected from our screening procedure as the most promising seawater and freshwater strains for biodiesel production. Table 5 shows a general comparison of the performances of the four promising strains selected in this study to those reported in the literature and belonging to the same species. In fact, microalgae metabolism is highly affected by the culture conditions making it difficult to directly compare the performance of the strains characterized in this study to those identified and reported in the literature due to the different experimental conditions applied during cultivation. Furthermore, for a given strain, performance is also affected by the PBR and culture mode as previously demonstrated by Pruvost and Cornet (2012). These authors illustrated that for a given photon flux density, areal biomass and lipid productivities are the only reliable method of comparing strain performance since these values are independent of PBR geometry. Unfortunately, most studies report only volumetric productivity making it difficult to compare the results obtained in this study with values reported in the literature. For example, Nannochloropsis sp. F\&MM24 reported by Rodolfi et al., (2009), had higher volumetric lipid productivity than $N$. gaditana CCMP527 selected in this study (Table 5), but it must be noted that in their work, they used a bubble column PBR in fed-batch mode illuminated from two sides by $200 \mu \mathrm{mol}_{\mathrm{h} v} / \mathrm{m}^{2} \mathrm{~s}^{-1}$. By contrast, our study used a flat-plate PBR in batch mode illuminated with $250 \mu \mathrm{mol}_{\mathrm{h} v} / \mathrm{m}^{2} \mathrm{~s}^{-1}$ from one side. However, $N$. gaditana CCMP527 accumulated a larger quantity of TAG by dry weight compared to Nannochloropsis strains screened in previous work (Rodolfi et al., 2009; Griffiths et al., 2012; Simionato et al., 2013; Boussiba et al., 1987). Likewise, P. kessleri UTEX2229 studied here, featured higher TAG content by dry weight then the strains identified in the work of Přibyl et al. (2012) belonging to the same microalgae species and it also showed higher areal TAG productivity than $N$. oculata studied by Van Vooren et al. (2012) in the same culture conditions.

Finally, the biomass and TAG productivities of the strains reported here can serve as first order estimates for mass-scale microalgae cultivation. They can also be used to compare to productivities of traditional agricultural resources such as soybean or palm oil. However, the productivities obtained in indoor PBRs exposed to continuous illumination do not translate directly to outdoor productivities due to the fluctuations in environmental conditions such as irradiance (Day/Night cycles) and temperature, all of which affect microalgae metabolism.

\section{Conclusion}

An efficient screening procedure on criteria important for biodiesel production was developed and led to the selection of Nannochloropsis gaditana CCMP527 and Parachlorella kessleri UTEX2229 as the most promising seawater and freshwater strains, respectively. They accumulated up to $40 \%$ DW TAG and featured areal TAG productivities of $2.3 \times 10^{-3}$ and $2.7 \times 10^{-3} \mathrm{~kg} \mathrm{~m}^{-2} \mathrm{~d}^{-1}$ which correspond to annual productivity of 10 and 8.28 tons of TAG per hectare, respectively. They also showed encouraging cell fragility to recover their intracellular TAG in wet environment. The TAG productivity obtained for these two strains could be further improved by optimizing their culture conditions.

\section{Acknowledgements}

This research was supported by the French National Research Agency project DIESALG (ANR-12-BIME-0001-02). AT is grateful to the AUF (Francophone University Association) and the Lebanese National Council for Scientific Research (CNRS) for their financial support. Authors thank Hélène MAREC and Benjamin LE GOUIC for configuring PBR's data acquisition and control system, and Delphine KUCMA and Candice PERRIER for assistance with lipid analysis.

\section{References}

Alabi, A., Tampier, D., Bibeau, E., 2009. Microalgae Technologies and Processes for Biofuels and Bioenergy Production in British Columbia: Current Technology, Suitability, and Barriers to Implementation, British Columbia.

Berges, J., Franklin, D., Harrison, P., 2001. Evolution of an artificial seawater medium: improvements in enriched seawater, artificial water over the last two decades. J. Phycol. 37 (6), 1138-1145.

Bligh, E.G., Dyer, W.J., 1959. A rapid method of total lipid extraction and purification. Can. J. Biochem. Physiol. 37 (8), 911-917.

Boussiba, S., Vonshak, A., Cohen, Z., Avissar, Y., Richmond, A., 1987. Lipid and biomass production by the halotolerant microalga Nannochloropsis salina. Biomass 12 (1), 37-47.

Breuer, G., Packo, P.L., Dirk, E.M., Draaisma, R.B., Wijffels, R.H., 2012. The impact of nitrogen starvation on the dynamics of triacylglycerol accumulation in nine microalgae strains. Bioresour. Technol. 124, 217-226.

Chisti, Y., 2007. Biodiesel from microalgae. Biotechnol. Adv. 25 (3), 294-306.

Chisti, Y., 2008. Biodiesel from microalgae beats bioethanol. Trends Biotechnol. 26 (3), 126-131.

Chisti, Y., 2013. Constraints to commercialization of algal fuels. J. Biotechnol. 167 (3), 201-214.

Cooney, M.J., Greg, Y., Ronald, P., 2011. Bio-oil from photosynthetic microalgae: case study. Bioresour. Technol. 102 (1), 166-177.

Cornet, J., Dussap, C., 2009. A Simple and reliable formula for assessment of maximum volumetric productivities in photobioreactors. Biotechnol. Progr. 25 (2), 424-435.

Folch, J. Lees, M., Sloane-Stanley, G.H., 1957. A simple method for the isolation and purification of total lipides from animal tissues. J. Biol. Chem. 226 (1), 497-509.

Gouveia, L., Oliveira, A.C., 2009. Microalgae as a raw material for biofuels production. J. Ind. Microbiol. Biotechnol. 36 (2), 269-274.

Griffiths, M.J., Van Hille, R.P., Harrison, S.T.L., 2012. Lipid productivity, settling potential and fatty acid profile of 11 microalgal species grown under nitrogen replete and limited conditions. J. Appl. Phycol. 24 (5), 989-1001. 
Halim, R., Danquah, M.K., Webley, P.A., 2012. Extraction of oil from microalgae for biodiesel production: a review. Biotechnol. Adv. 30 (3), 709-732.

Hannon, M., Gimpel, J., Tran, M., Beth, R., Mayfield, S., 2010. Biofuels from algae: challenges and potential. Biofuels 1 (5), 763-784.

Hempel, N., Petrick, I., Behrendt, F., 2012. Biomass productivity and productivity of fatty acids and amino acids of microalgae strains as key characteristics of suitability for biodiesel production. J. Appl. Phycol. 24, 1407-1418.

Ho, S.H., Chen, C.Y., Chang, J.S., 2012. Effect of light intensity and nitrogen starvation on $\mathrm{CO}_{2}$ fixation and lipid/carbohydrate production of an indigenous microalga scenedesmus obliquus CNW-N. Bioresour. Technol. 113, 244-252.

Hu, Q., Sommerfeld, M., Jarvis, E., Ghirardi, M., Posewitz, M., Seibert, M., Darzins, A., 2008. Microalgal triacylglycerols as feedstocks for biofuel production: perspectives and advances. Plant. J. 54 (4), 621-639.

Islam, M.A., Magnusson, M., Brown, R.J., Ayoko, G.A., Nabi, M.N., Heimann, K., 2013. Microalgal species selection for biodiesel production based on fuel properties derived from fatty acid profiles. Energies 6 (11), 5676-5702.

Jubeau, S., Marchal, L., Pruvost, J., Jaouen, P., Legrand, J., Fleurence, J., 2013. High pressure disruption: a two-step treatment for selective extraction of intracellular components from the microalga porphyridium cruentum. J. Appl. Phycol. 25 (4), 983-989.

Kandilian, R., Pruvost, J., Legrand, J., Pilon, L., 2014. Influence of light absorption rate by nannochloropsis oculata on triglyceride production during nitrogen starvation. Bioresour. Technol. 163, 308-319.

Knothe, G., 2005. Dependence of biodiesel fuel properties on the structure of fatty acid alkyl esters. Fuel Process. Technol. 86 (10), 1059-1070.

Knothe, G., 2009. Improving biodiesel fuel properties by modifying fatty ester composition. Energy Environ. Sci. 2 (7), 759-766.

Li, Y.G., Xu, L., Huang, Y.M., Wang, F., Guo, C., Liu, C.Z., 2011. Microalgal biodiesel in china: opportunities and challenges. Appl. Energy 88 (10), 3432-3437.

Mata, T.M., Martins, A.A., Caetano, N., 2010. Microalgae for biodiesel production and other applications: a review. Renewable Sustainable Energy Rev. 14 (1), 217-232.

Montalescot, V., Rinaldi, T., Touchard, R., Jubeau, S., Frappart, M., Jaouen, P., Bourseau, P., Marchal, L., 2015. Optimization of bead milling parameters for the cell disruption of microalgae: process modeling and application to Porphyridium Cruentum and Nannochloropsis Oculata. Bioresour. Technol. 196, 339-346.

Onodera, J., Ohsumi, Y., 2005. Autophagy is required for maintenance of amino acid levels and protein synthesis under nitrogen starvation. J. Biol. Chem. 280 (36), 31582-31586.

Perrier, B., Crampon, C., Guézet, O., Simon, C., Maire, F., Lépine, O., Pruvost, J., Lozano, P., Bernard, O., Badens, E., 2015. Production of a methyl ester from the microalgae Nannochloropsis grown in raceways on the French west coast. Fuel 153, 640-649.

Přibyl, P., Cepák, V., Zachleder, V., 2012. Production of lipids in 10 strains of chlorella and parachlorella, and enhanced lipid productivity in chlorella vulgaris. Appl. Microbiol. Biotechnol. 94 (2), 549-561.
Pruvost, J., Cornet, J., 2012. Knowledge models for the engineering and optimization of photobioreactors. In: Posten, Dans C., Walter, C. (Eds.), Microalgae Biotechnology. De Gruyter, Berlin, Germany, pp. 181-224.

Pruvost, J., Cornet, J.F., Legrand, J., 2008. Hydrodynamics influence on light conversion in photobioreactors: an energetically consistent analysis. Chem. Eng. Sci. 63 (14), 3679-3694.

Pruvost, J., Van Vooren, G., Cogne, G., Legrand, J., 2009. Investigation of biomass and lipids production with Neochloris oleoabundans in photobioreactor. Bioresour. Technol. 100 (23), 5988-5995.

Pruvost, J., Van Vooren, G., Le Gouic, B., Couzinet-Mossion, A., Legrand, J., 2011. Systematic investigation of biomass and lipid productivity by microalgae in photobioreactors for biodiesel application. Bioresour. Technol. 102 (1), 150 158.

Rawat, I., Ranjith Kumar, R., Mutanda, T., Bux, F., 2013. Biodiesel from microalgae: a critical evaluation from laboratory to large scale production. Appl. Energy 103, 444-467.

Rodolfi, L., Chini Zittelli, G., Bassi, N., Padovani, G., Biondi, N., Bonini, G., Tredici, M.R., 2009. Microalgae for oil: strain selection, induction of lipid synthesis and outdoor mass cultivation in a low-cost photobioreactor. Biotechnol. Bioeng. 102 (1), 100-112.

Scott, S.A., Davey, M.P., Dennis, J.S., Horst, I., Howe, C.J., Lea-Smith, D.J., Smith, A.G. 2010. Biodiesel from algae: challenges and prospects. Energy Biotechnol Environ. Biotechnol. 21 (3), 277-286.

Simionato, D., Block, M., La Rocca, N., Jouhet, J., Marechal, E., Finazzi, G., et al., 2013. The Response of Nannochloropsis gaditana to Nitrogen Starvation Includes De Novo Biosynthesis of Triacylglycerols, a Decrease of Chloroplast Galactolipids, and Reorganization of the Photosynthetic Apparatus. Eukaryotic Cell 12 (5), 665-676.

Stansell, G.R., Gray, V.M., Sym, S.D., 2012. Microalgal fatty acid composition: implications for biodiesel quality. J. Appl. Phycol. 24 (4), 791-801.

Taleb, A., 2015. Production de biodiesel à partir des microalgues: recherche des souches accumulatrices de lipides et optimisation des conditions de culture en photobioréacteurs (Doctoral dissertation).

Taleb, A., Pruvost, J., Legrand, J., Marec, H., Le-Gouic, B., Mirabella, B., Legeret, B. 2015. Development and validation of a screening procedure of microalgae for biodiesel production: application to the genus of marine microalgae nannochloropsis. Bioresour. Technol. 177, 224-232.

Van Vooren, G., Le Grand, F., Legrand, J., Cuiné, S., Peltier, G., Pruvost, J., 2012 Investigation of fatty acids accumulation in nannochloropsis oculata for biodiesel application. Bioresour. Technol. 124, 421-432.

Wu, J., James Jr, D.W., Dooner, H.K., Browse, J., 1994. A mutant of arabidopsis deficient in the elongation of palmitic acid. Plant Physiol. 106, 143-150. 